\title{
Optimizing the mercerisation effect on the mode I fracture toughness of Bambusa Vulgaris bamboo using surface response method.
}

\author{
HASSAN, M.Z., ROSLAN, S.A., RASID, Z.A., YUSOFF, M.Z.M., SAPUAN, \\ S.M. and MUHAMMAD-SUKKI, F.
} stored or distributed in any form or by any means, electronic or mechanical, including photocopying, without written permission from the publisher. 


\section{Implementation and Evaluation of Green Materials in Technology Development:}

\section{Emerging Research and Opportunities}

M.T. Mastura

Universiti Teknikal Malaysia Melaka, Malaysia

S. M. Sapuan

Universiti Putra Malaysia, Malaysia 
Published in the United States of America by

IGI Global

Engineering Science Reference (an imprint of IGI Global)

701 E. Chocolate Avenue

Hershey PA, USA 17033

Tel: $717-533-8845$

Fax: 717-533-8661

E-mail: cust@igi-global.com

Web site: http://www.igi-global.com

Copyright ( 2020 by IGI Global. All rights reserved. No part of this publication may be reproduced, stored or distributed in any form or by any means, electronic or mechanical, including photocopying, without written permission from the publisher.

Product or company names used in this set are for identification purposes only. Inclusion of the names of the products or companies does not indicate a claim of ownership by IGI Global of the trademark or registered trademark.

\section{Library of Congress Cataloging-in-Publication Data}

Names: Mastura, M. T., 1985- editor. I Sapuan, S. M., editor.

Title: Implementation and evaluation of green materials in technology development: emerging research and opportunities / M.T. Mastura and S.M. Sapuan, editors.

Description: Hershey, PA : Engineering Science Reference, 2020. I Includes bibliographical references and index. I Summary: "'This book explores the theoretical, conceptual, and practical uses of environmentally friendly materials in technology development"--Provided by publisher"-Provided by publisher.

Identifiers: LCCN 2019027710 (print) | LCCN 2019027711 (ebook) | ISBN 9781799813743 (hardcover) I ISBN 9781799813750 (paperback) I ISBN 9781799813767 (ebook)

Subjects: LCSH: Technology--Environmental aspects. I Materials--Environmental aspects. I Sustainable engineering.

Classification: LCC T173.8 .E93 2020 (print) I LCC T173.8 (ebook) I DDC $600--d c 23$

LC record available at https://lccn.loc.gov/2019027710

LC ebook record available at https://lccn.loc.gov/2019027711

This book is published in the IGI Global book series Advances in Environmental Engineering and Green Technologies (AEEGT) (ISSN: 2326-9162; eISSN: 2326-9170)

British Cataloguing in Publication Data

A Cataloguing in Publication record for this book is available from the British Library.

All work contributed to this book is new, previously-unpublished material.

The views expressed in this book are those of the authors, but not necessarily of the publisher.

For electronic access to this publication, please contact: eresources@igi-global.com. 


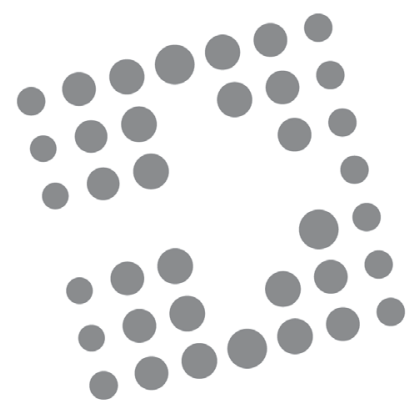

\title{
Advances in Environmental Engineering and Green Technologies (AEEGT) Book Series
}

\author{
ISSN:2326-9162 \\ EISSN:2326-9170
}

Editor-in-Chief: Sang-Bing Tsai, University of Electronic Science and Technology of China Zhongshan Institute, China; Ming-Lang Tseng, Lunghwa University of Science and Technology, Taiwan; and Yuchi Wang, University of Electronic Science and Technology of China Zhongshan Institute, China

\section{MISSION}

Growing awareness and an increased focus on environmental issues such as climate change, energy use, and loss of non-renewable resources have brought about a greater need for research that provides potential solutions to these problems. Research in environmental science and engineering continues to play a vital role in uncovering new opportunities for a "green" future.

The Advances in Environmental Engineering and Green Technologies (AEEGT) book series is a mouthpiece for research in all aspects of environmental science, earth science, and green initiatives. This series supports the ongoing research in this field through publishing books that discuss topics within environmental engineering or that deal with the interdisciplinary field of green technologies.

\section{COVERAGE}

- Air Quality

- Waste Management

- Sustainable Communities

- Electric Vehicles

- Green Transportation

- Industrial Waste Management and Minimization

- Green Technology

- Contaminated Site Remediation

- Radioactive Waste Treatment

- Water Supply and Treatment

The Advances in Environmental Engineering and Green Technologies (AEEGT) Book Series (ISSN 2326-9162) is published by IGI Global, 701 E. Chocolate Avenue, Hershey, PA 17033-1240, USA, www.igi-global.com. This series is composed of titles available for purchase individually; each title is edited to be contextually exclusive from any other title within the series. For pricing and ordering information please visit http://www.igi-global.com/book-series/advances-environmental-engineering-greentechnologies/73679. Postmaster: Send all address changes to above address. Copyright $\odot 2020$ IGI Global. All rights, including translation in other languages reserved by the publisher. No part of this series may be reproduced or used in any form or by any means - graphics, electronic, or mechanical, including photocopying, recording, taping, or information and retrieval systems without written permission from the publisher, except for non commercial, educational use, including classroom teaching purposes. The views expressed in this series are those of the authors, but not necessarily of IGI Global. 


\section{Titles in this Series}

For a list of additional titles in this series, please visit:

https://www.igi-global.com/book-series/advances-environmental-engineering-green-technologies/73679

Modern Techniques for Agricultural Disease Management and Crop Yield Prediction N. Pradeep (Bapuji Institute of Engineering and Technology, India) Sandeep Kautish (Lord Buddha Education Foundation, Nepal \& Asia Pacific University, Malaysia) C.R. Nirmala (Bapuji Institute of Engineering and Technology, India) Vishal Goyal (Punjabi University, Patiala, India) and Sonia Abdellatif (Seoul National University, South Korea)

Engineering Science Reference • C $2020 \bullet 291$ pp • H/C (ISBN: 9781522596325) • US $\$ 195.00$ (our price)

\section{Novel Advancements in Electrical Power Planning and Performance}

Smita Shandilya (Sagar Institute of Research, Technology and Science, India) Shishir Kumar Shandilya (Vellore Institute of Technology, India) Tripta Thakur (Maulana Azad National Institute of Technology, India) and Atulya K. Nagar (Liverpool Hope University, UK) Engineering Science Reference • (C) $2020 \bullet 388 p p \bullet$ H/C (ISBN: 9781522585510) • US $\$ 225.00$ (our price)

\section{Global Food Politics and Approaches to Sustainable Consumption Emerging Research} and Opportunities

Luke Amadi (University of Port Harcourt, Nigeria) and Fidelis Allen (University of Port Harcourt, Nigeria)

Engineering Science Reference • (C) $2020 \bullet 242 p p \bullet H / C$ (ISBN: 9781799801252) • US $\$ 185.00$ (our price)

\section{Fuzzy Expert Systems and Applications in Agricultural Diagnosis}

A.V. Senthil Kumar (Hindusthan College of Arts and Science, India) and M. Kalpana (Tamil Nadu Agricultural University, India)

Engineering Science Reference • C $2020 \bullet 335 p p \bullet H / C$ (ISBN: 9781522591757) • US $\$ 245.00$ (our price)

Handbook of Research on Environmental and Human Health Impacts of Plastic Pollution Khursheed Ahmad Wani (Government Degree College Bijbehara, India) Lutfah Ariana (Indonesian Institute of Sciences, Indonesia) and S.M. Zuber (Government Degree College Bijbehara, India)

Engineering Science Reference • (C) $2020 \bullet 600 \mathrm{pp} \bullet \mathrm{H} / \mathrm{C}$ (ISBN: 9781522594529) • US $\$ 285.00$ (our price)

\section{IGIGlobal

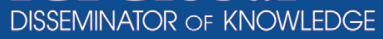

701 East Chocolate Avenue, Hershey, PA 17033, USA

Tel: 717-533-8845 x100 • Fax: 717-533-8661

E-Mail: cust@igi-global.com • www.igi-global.com 


\section{Table of Contents}

Preface

viii

\section{Chapter 1}

Green Material for Fused Filament Fabrication: A Review 1

Mastura Mohammad Taha, Universiti Teknikal Malaysia Melaka, Malaysia

Ridhwan Jumaidin, Universiti Teknikal Malaysia Melaka, Malaysia

Nadlene M. Razali, Universiti Teknikal Malaysia Melaka, Malaysia

Syahibudil Ikhwan Abdul Kudus, Universiti Teknikal Malaysia Melaka,

Malaysia

\section{Chapter 2}

Starch Cellulosic Bio-Composites: A Sustainable and Multifunctional

Material for Green Technology

M. J. Halimatul, Universiti Putra Malaysia, Malaysia

S. M. Sapuan, Universiti Putra Malaysia, Malaysia

N. Julkapli, Universiti Malaya

M. Jawaid, Universiti Putra Malaysia, Malaysia

M. R. Ishak, Universiti Putra Malaysia, Malaysia

Mohammad Taha Mastura, Universiti Teknikal Malaysia Melaka,

Malaysia

\section{Chapter 3}

Green Materials in Hybrid Composites for Automotive Applications: Green

Materials .56

N. M. Norizan, Universiti Putra Malaysia, Malaysia

A. Atiqah, Universiti Tenaga Nasional, Malaysia

M. N. M. Ansari, Universiti Tenaga Nasional, Malaysia

M. Rahmah, Universiti Teknologi MARA, Malaysia 


\section{Chapter 4}

Modifications of Biodegradable Thermoplastic Starch (TPS) From Sago

Starch via Cross-Linking Method

Yusriah Lazim, Malaysian Institute of Chemical Bio-Engineering

Technology, Universiti Kuala Lumpur, Malaysia

Abdul Baith Abu Hanafi, Malaysian Institute of Chemical Bio-

Engineering Technology, Universiti Kuala Lumpur, Malaysia

Mohd Syazwan Adura, Malaysian Institute of Chemical Bio-Engineering

Technology, Universiti Kuala Lumpur, Malaysia

Siti Afifah Muda, Malaysian Institute of Chemical Bio-Engineering

Technology, Universiti Kuala Lumpur, Malaysia

Lily Suhaila Yacob, Malaysian Institute of Chemical Bio-Engineering

Technology, Universiti Kuala Lumpur, Malaysia

Ahmad Marzio Mohd Yusof, Malaysian Institute of Chemical Bio-

Engineering Technology, Universiti Kuala Lumpur, Malaysia

\section{Chapter 5}

Non-Edible Oil Biodiesel Production via Microwave Irradiation Technologies

Using Waste-Heterogeneous Catalyst Derived From Natural Calcium Oxide ....92

Mahanum Mohd Zamberi, Universiti Teknikal Malaysia Melaka, Malaysia

Farid Nasir Ani, Universiti Teknologi Malaysia, Malaysia

\section{Chapter 6}

Optimizing the Mercerisation Effect on the Mode I Fracture Toughness of

Bambusa Vulgaris Bamboo Using Surface Response Method.

Mohamad Zaki Hassan, Universiti Teknologi Malaysia, Malaysia

Siti Amni Roslan, Universiti Teknologi Malaysia, Malaysia

Zainudin A. Rasid, Universiti Teknologi Malaysia, Malaysia

Mohd Zuhri Mohamed Yusoff, Universiti Putra Malaysia, Malaysia

S. M. Sapuan, Universiti Putra Malaysia, Malaysia

Firdaus Muhammad-Sukki, Robert Gordon University, UK

\section{Chapter 7}

Investigation of Recycled Acrylonitrile Butadiene Styrene for Additive Manufacturing 130

Shajahan Bin Maidin, Universiti Teknikal Malaysia Melaka, Malaysia

Zulkeflee Abdullah, Universiti Teknikal Malaysia Melaka, Malaysia

Ting Kung Hieng, Universiti Teknikal Malaysia Melaka, Malaysia 
Related Readings.

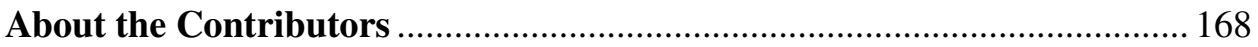

Index 


\title{
Chapter 6 \\ Optimizing the Mercerisation Effect on the Mode I Fracture Toughness of Bambusa Vulgaris Bamboo Using Surface Response Method
}

\author{
Mohamad Zaki Hassan \\ (iD) https://orcid.org/0000-0002-2321-0604 \\ Universiti Teknologi Malaysia, Malaysia \\ Siti Amni Roslan \\ Universiti Teknologi Malaysia, Malaysia \\ Zainudin A. Rasid \\ Universiti Teknologi Malaysia, Malaysia \\ Mohd Zuhri Mohamed Yusoff \\ Universiti Putra Malaysia, Malaysia \\ S. M. Sapuan \\ Universiti Putra Malaysia, Malaysia \\ Firdaus Muhammad-Sukki \\ iD https://orcid.org/0000-0002-5415-2259 \\ Robert Gordon University, UK
}




\section{ABSTRACT}

Alkaline treatment is widely being promoted to treat natural fibres and improves the fibre bundle surface for better interlocking with the polymer matrix. The aim of this study is to optimize the merceration parameter including natrium hydroxide ( $\mathrm{NaOH})$ concentration, soaking and drying time for Bambusa Vulgaris bamboo using response surface methodology (RSM). Here, the treatment conditions were employed by the Box-Behnken design (BBD). The comparative study of the treated and untreated fibre on crack propagation behaviour, Mode I interlaminarfracture toughness (GIC) of the bamboo along the longitudinal direction test was carried out. Through the statistical analysis approach (ANOVA), it is suggested that bamboo treated with $1.5 \mathrm{wt}$.\% concentration of $\mathrm{NaOH}$ is capable to reach the fracture toughness value up to $367.25 \mathrm{~J} / \mathrm{m} 2$. It is also shown that all proposed variables for treatment in this study (i.e., the concentration of the $\mathrm{NaOH}$ is highly significant with the 2.85 hours of soaking and drying for 72.5 hours).

\section{INTRODUCTION}

Normally, fiber reinforced polymer materials are laminate composites consisting of high strength of synthetic fibers (i.e. glass, carbon and kevlar) reinforcement in polymeric matrices. The reinforcement by those fibers provides the polymer substantially enhanced mechanical properties and makes the fiber reinforced polymer composites suitable for a large number of diverse applications. Although this synthetic fiber reinforced polymer possess exclusive mechanical strength, they have also got some serious drawbacks such as high cost, poor recycling and nonbiodegradable properties.

For these reasons, natural plant fibers reinforced polymer composites are increasingly gaining attention as viable alternative to replace the synthetic fiber reinforced polymer counterpart. These renewable fiber closely high specific strength to weight ratio and offering less abrasion as compared to glass fibers. Many researcher has studied the mechanical properties of these natural fibers such as bamboo, kenaf and jute (Chen et al., 2017; Bakhori et al., 2017; Bakhori, Zuikafly, Ahmad, \& Hassan, 2017). Interestingly, fiber derived from bamboos have attracted more interests due to their offering higher performance and plenty sources for production (Yu, Jiang, Fei, Wang, \& Wang, 2011).

In addition, an extensively study have been conducted on chemical treatment for natural fiber. This treatment is being suggested in order to decrease the incompatibility between natural fibre and polymer matrix due to hydrophilic and hydrophobic interaction. The common alkaline treatment $(\mathrm{NaOH})$ on natural fibre has been considered as one of most popular and cost affective methods. The effect of chemical 
treatments of the bamboo fiber is reported by Yang et al. (2017). They immersed the bamboo fibers in a $\mathrm{NaOH}$ solution of 5, 10 and $25 \%$ concentration for further removing hemicellulose and heated at $75{ }^{\circ} \mathrm{C}$ for $2 \mathrm{~h}$ in a water bath. It is found that a higher concentration of $\mathrm{NaOH}$ degrades the long chain cellulose molecules at the fiber interface and consequently, weakens fiber load transfer. Reddy and Dhoria (2018) examined the effect of $\mathrm{NaOH}$ concentrations of $5 \%(\mathrm{w} / \mathrm{t})$ on kenaf fibre reinforced composites. Mechanical testings including tensile, flexural and impact are obtained to determine tensile strength, bending and impact strength of the composites. It is found that the chemically treated fiber composites offer good mechanical properties compared to untreated fibers. Similarly, Mishra et al. (2003) reported that sisal fibre treated with $5 \%$ concentration of $\mathrm{NaOH}$ exhibited good tensile properties than those treated with $10 \%$ of alkaline concentration. They suggested that the excessive alkali concentration would cause delignification and weaken the sisal fibre. On the other hand, a comprehensive characterization of wettability and interfacial properties of kenaf fibers polyester composites fabricated by resin transfer molding is reported by Ariawan et al. (2017). Here, kenaf fibers are chemically modified by immersing in $6 \% \mathrm{NaOH}$ concentration for 1 to $5 \mathrm{~h}$ to enhance the interaction between fiber and matrices. In order to investigate the effect of soaking time, surface energy and the interlaminar shear strength value of the composites are evaluated. They reported that $3 \mathrm{~h}$ treated of kenaf fiber composite enhanced the interface bonding characteristic of the composite laminate. Furthermore, the effect of alkali treatment under various conditions on physical properties of kenaf fiber is investigated by Khan et al. (Khan, Yousif, \& Islam, 2017). In this study, kenaf fiber were treated at alkali concentrations 2, 6 and $10(\mathrm{w} / \mathrm{v} \%)$, immersion durations at 30,240 and 480 minute and temperatures at 27,60 and $100^{\circ} \mathrm{C}$. Kenaf fiber weight loss and density value are decreased after alkali treatment compared to untreated kenaf fiber. Furthermore, Rao et al. (2010) reported that $1 \%$ concentration of $\mathrm{NaOH}$ is the optimum condition to treat bamboo polymeric composite. On the other hand, few studies claimed that a higher $\mathrm{NaOH}$ concentration is the best in treating natural fibre (Yan, Chouw, Huang, \& Kasal, 2016) and capable of removing excess moisture thoroughly. In spite of that, the $\mathrm{NaOH}$ concentration is the most dominant factor that gives effect on the natural fibre and still remain inconsistency.

Various technique have been explored by researchers to accurately determine the optimum condition for alkaline treatment of the natural fiber. Singh, Mukhopadhyay, \& Das (2017)used a three-factor and three-level Box-Behnken design method to optimize the mass fraction of fibres, percentage of crosslinking and plasticizing agent. Initialy, they treated the sugarcane baggase fiber with $6 \%$ of sodium hydroxide. Liu et al. (2018) suggested optimized solution using the Box-Benhken design for pretreatment of corn straw by the alkaline solution. Under the optimized conditions, the cellulose and hemicellulose of the corn straw increased and the lignin content 
was also reduced. Furthermore, a three-level Box-Behnken design, which is subset of the response surface methodology (RSM), has been investigated by Yaghoobi and Fereidoon (2018). The effect of three independent variables incuding kenaf fiber load, fiber length and polypropylene-grafted maleic anhydride (PP-g-MA) compatibilizer content have been investigated on the tensile strength and modulus of the biocomposite. The optimal tensile strength and tensile modulus are to be 32.70 $\mathrm{MPa}$ and 2,182.33 MPa, respectively; and achieved at $28.95 \mathrm{wt} \%$ of the kenaf fiber, fiber length of $6.22 \mathrm{~mm}$ and PP-g-MA content of $5 \mathrm{wt} \%$.

In this study, the Box-Behnken design (BBD) of the response surface method is employed to obtain an experimental design of alkaline treatment conditions for the bambusa vulgaris bamboo. Three experimental conditions including the concentration of $\mathrm{NaOH}$, soaking and drying time are considered. Mode I interlaminar fracture toughness $\left(G_{I C}\right)$ test is conducted to investigate the effect of alkaline treatment conditions on crack propagation behaviour along the longitudinal direction of the bamboo.

\section{EXPERIMENTAL METHOD}

\section{Box-Benhken Design Iteration}

Table 1 shows the design points for low, middle and high level of each variable conditions. This input data then was randomized and modelled by BBD using the Design-expert (6.0.8) software. It offers a total number of 17 experimental runs that include of 12 runs and 5 replication runs of the centre point.

\section{Material and Testing}

The bamboo material used in this study belongs to bambusa vulgaris family. The raw bamboo is cut approximately 5 metres above the ground. The age of bamboo is approximately four years old and taken from Jeli, Kelantan at the north-eastern

Table 1. The initial setting of Box-Behnken design (BBD)

\begin{tabular}{|c|c|c|c|c|}
\hline \multirow{2}{*}{ Factors / Independent Variables } & \multirow{2}{*}{ Symbols } & \multicolumn{3}{|c|}{ Coded and Actual Levels } \\
\cline { 3 - 5 } & & Low (-1) & Middle (0) & High (+1) \\
\hline Concentration of NaOH (\%) & $\mathrm{X}_{1}$ & 1 & 2 & 3 \\
\hline Soaking duration (hours) & $\mathrm{X}_{2}$ & 3 & 6 & 9 \\
\hline Drying duration (hours) & $\mathrm{X}_{3}$ & 2 & 48 & 72 \\
\hline
\end{tabular}


state of Malaysia. The Mode I testing specimens are prepared as a double cantilever beam (DCB) according to the ASTM D5528 standard (ASTM D5528, 2001). The smaller parts of dried bamboo culm are trimmed into narrow strips and those strips were edge squared. The dimension of the DCB specimen is, longitudinal direction, $w=200 \mathrm{~mm}$; tangential direction, $h=20 \mathrm{~mm}$; and radial thickness, $b=9 \mathrm{~mm}$ with initial crack length, $\alpha_{0}=40 \mathrm{~mm}$. Initially, two holes of $5 \mathrm{~mm}$ in diameter are made at the point crack initiation as shown in Figure 1.

Following this, the specimens are chemically treated with an alkali solution. The concentration of this solution, sodium hydroxide $(\mathrm{NaOH})$, is prepared by weight per volume $(w / v)$ percentage. Here, 1 gram of $\mathrm{NaOH}$ pellets is diluted in $100 \mathrm{ml}$ of distilled water to obtain $1 \mathrm{wt} . \%$ concentration of $\mathrm{NaOH}$. After undergoing alkali treatment and drying process, an initial crack is cleaved along the middle-line of the bamboo DCB specimen parallel to grain by a stiff razor. The length of the initial crack $\left(\alpha_{0}\right)$ controlled at $40 \mathrm{~mm}$ from the centre of the loading holes. The purpose of this cut is to stimulate a naturally sharp crack during the test. Then, the crack tip is marked to obtain correct pre-crack length. Later, the bamboo DCB specimen is fitted to the U-shaped hook steel which connected to a $10 \mathrm{kN}$ load cell on a Shidmazu universal testing machine as illustrated in Figure 2.

The test performed at a crosshead displacement rate of $1 \mathrm{~mm} / \mathrm{min}$ with five specimens tested at each treatment conditions. During loading, the crack propagated in the bamboo DCB specimen is measured. The corresponding applied load versus the opening displacement $(F-\delta)$ is recorded by a computer. Once the load $(F)$ suddenly dropped, the loading machine stopped. Here, the crack tip on the inner $\left(\alpha_{\text {linner }}\right)$ and outer $\left(\alpha_{\text {louter }}\right)$ parts of the specimen are marked and the average value is taken as the

\section{Figure 1. Schematic diagram of DCB specimen}

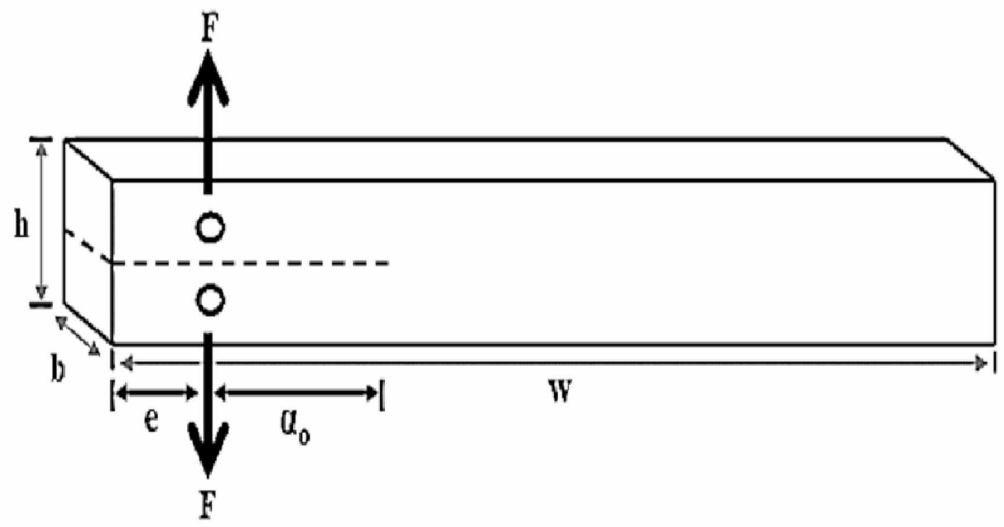


Figure 2. Schematic diagram of DCB specimen connected to U-hook

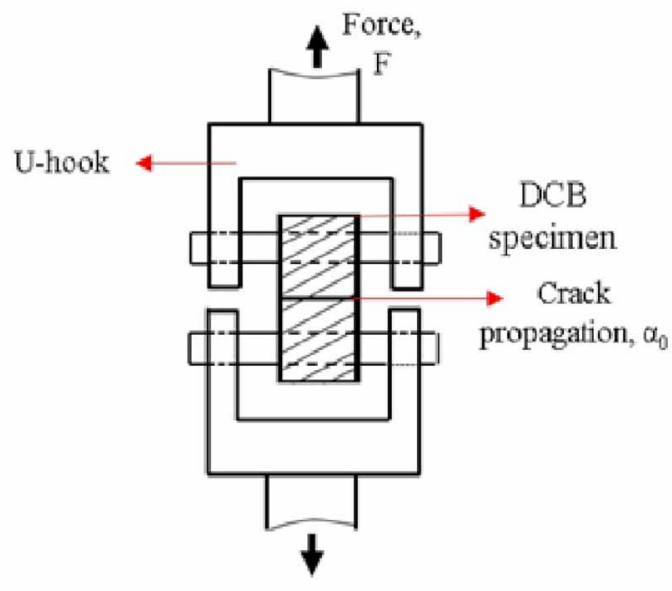

corresponding crack length $\left(\alpha_{1}\right)$. Afterwards, the specimen is unloaded and reloaded repeatedly until the specimen completely fractured. The equivalent crack length $\alpha_{2}$, $\alpha_{3}, \alpha_{4} \ldots \alpha_{n}$ can be obtained and recorded.

\section{$G_{I C}$ Analysis}

The Mode I interlaminar fracture toughness $\left(G_{I C}\right)$ is measured by symmetric bending tests using the DCB specimen. Hence, the energy release rate $G$ of interlaminar fracture mode can be calculated according to Equation 1.

$G=\frac{1}{b} \cdot \frac{\mathrm{d} U}{\mathrm{~d} a}$

where $U$ is the total strain energy in the test specimen, $b$ is the specimen width, and $a$ is the delamination length. Then, $U$ can also be written as

$U=\frac{1}{2} F \delta=\frac{1}{2} F^{2} C$

where $F$ is the load, $\delta$ is opening displacement of the DCB specimen and $C$ is the DCB specimen compliance $(\delta / F)$ namely the reciprocal of the slope $(k)$. It can be calculated based on two points from the $F-\delta$ traces obtained. The relationship between them can be explained in the following Equation 3 . 
$C=\frac{1}{k}=\frac{\delta_{2}-\delta_{1}}{F_{2}-F_{1}}$

So, the Mode I interlaminar fracture toughness $\left(G_{I C}\right)$ is calculated using Equation 4.

$G_{I C}=-\frac{1}{b} \cdot \frac{d\left(-\frac{1}{2} F c r^{2} C\right)}{d a}=\frac{F c r^{2}}{2 b} \cdot \frac{d c}{d a}$

where $F c r$ is the critical load. It is only necessary to measure the differential increase in compliance $(\mathrm{d} C)$ depending on the differential increase in the crack length $(\mathrm{d} a)$.

According to the compliance method, the reciprocal of the slope is the corresponding compliance $(\mathrm{Ci})$ of the DCB specimen with a certain crack length $\left(\alpha_{\mathrm{i}}\right)$. The relationship between $C$ and $\alpha$ can be described as stated in following Equation 5 .

$C=q \alpha \mathrm{m}$

where $q$ and $m$ are the fitting coefficients of the compliance curve of the DCB specimen. So, after taking a logarithm of Equation 5, the equation meets the linear model as stated in Equation 6.

$\lg C=\lg q+m \lg \alpha$

Following the Mode I test, the results are analysed and evaluated statistically using the Analysis of Variance (ANOVA).

\section{ESULTS AND DISCUSSION}

\section{GI ${ }_{c}$ Characterization of Bamboo DCB Specimen}

A typical force-displacement trace of an untreated bamboo specimen for a $42 \mathrm{~mm}$ of crack length $\left(\alpha_{1}\right)$ is shown in Figure 3. Initially, the trace increase linearly from the loading start to the maximum force. It begins to waver after a while due to the overbearing load capacity, which caused unstable crack propagation along the longitudinal direction of bamboo DCB specimen. Subsequently, the trace drops and the test suddenly stopped. At this point, maximum force is recorded as the critical force, $F_{\mathrm{cr}}$, to indicate the decisive point of rapid cracking in the bamboo specimen.

Figure 4 shows an untreated bamboo DCB specimen subjected to the multi-point method of the Mode I fracture testing. The opening crack lengths for the outer layer 
of the bamboo that was recorded approximately 1 to $2 \mathrm{~mm}$ longer than those of the inner layer as can be seen in Figure 4. A similar observation also recorded on the treated bamboo DCB specimens. Shao, Fang, and Tian (2009) reported the resistance against crack propagation of bamboo is controlled by interlaminar strength between the bamboo fibres. As the amount of bamboo fibres on the outer layer is less than that of the inner layer, resistance against crack propagation exhibited by the outer layer is weaker. It indicates that the outer layer has lower interlaminar strength than the inner layer as described in (Shao, Fang, \& Tian, 2009).

Table 2 summarises the average $G_{I C}$ values for bamboo specimens with the corresponding treatment conditions subjected to Mode I testing. From the table, it can be seen that all of the treated specimens exhibited lower $G_{I C}$ values compared to untreated specimens. The average of $G_{\text {IC }}$ value for untreated bamboo specimens is recorded at $365.20 \mathrm{~J} / \mathrm{m}^{2}$. In contrast, the highest average $G_{I C}$ value for the treated bamboo is shown by the treatment condition No.1, which is $362.85 \mathrm{~J} / \mathrm{m}^{2}$. The lowest $G_{I C}$ value is found at the treatment condition No.13, exhibited more than half $G_{I C}$ value of the treatment condition No.1. The lower $G_{I C}$ value of treated bamboo specimens may be attributed to the softening effect caused by alkaline treatment which influences the stress transfer process along the specimen during the test is conducted (Shao, Fang, \& Tian, 2009). It should be noted that even though the presence of alkaline lowers the value of the mean, $G_{I C}$, in the natural fibre composite application, the alkaline will improve the bonding between the fibre and the matrix and improve the mechanical properties of the composite.

Figure 3. The typical force-displacement trace of an untreated bamboo specimen

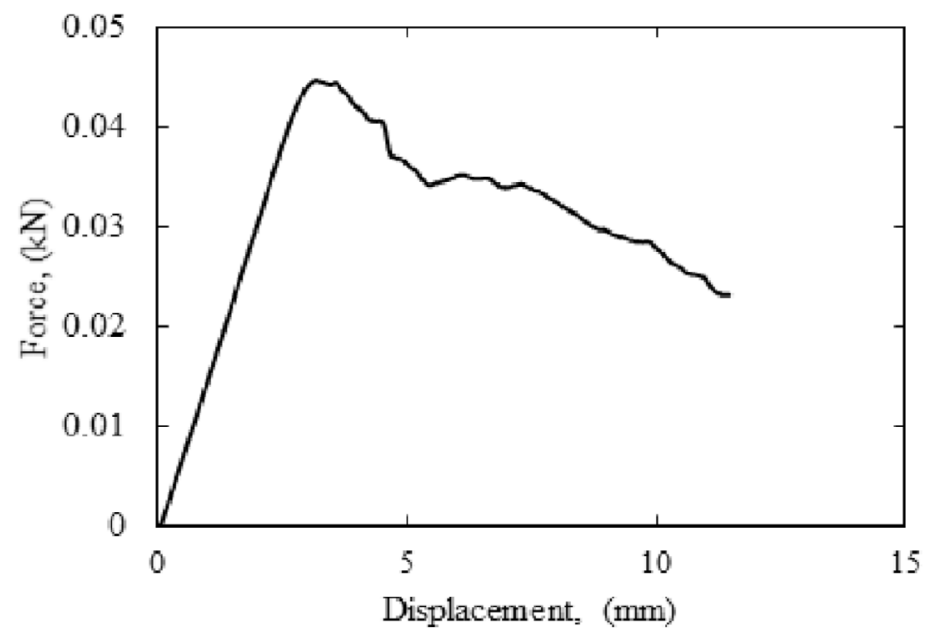


Figure 4. The delamination of crack lengths with geometric views for (a) the outer and $(b)$ the inner parts of an untreated bamboo DCB specimen

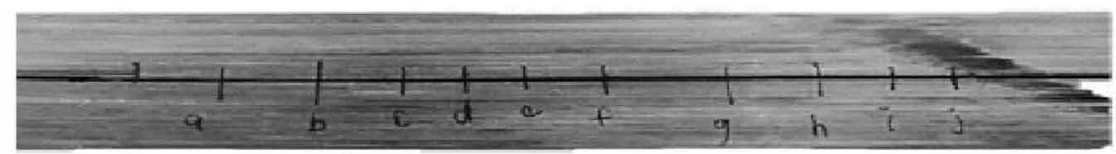

(a)
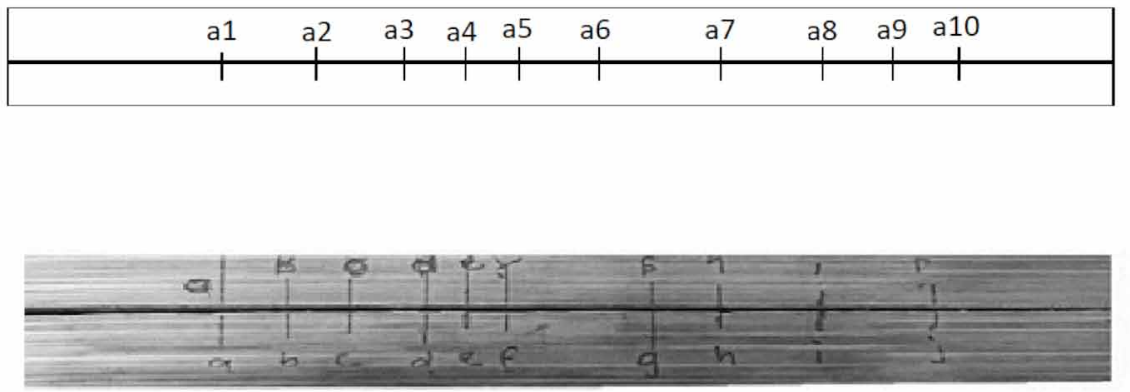

(b)
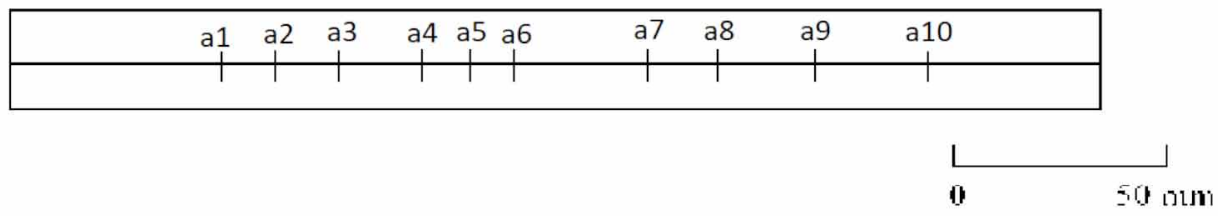

\section{Quadratic Model Fitting and Analysis of Variance (ANOVA)}

The $G_{I C}$ results of treated bamboo are further investigated using analysis of variance (ANOVA) to determine which variables that significantly affect the $G_{I C}$ value of treated bamboo. By applying a multiple regression analysis of the responses, the outcome proposed the highest order polynomial in which the additional terms are significant and the model is not aliased. Following that, backwards elimination method was applied to exclude insignificant terms automatically. The ANOVA for the reduced quadratic models that summarised in the $G_{I C}$ value, is shown in Equation 7.

$$
\begin{aligned}
& G_{I C}=573.235-160.801 X_{1}-14.743 X_{2}-1.229 X_{3}+27.696 X_{1}^{2}-0.679 X_{2}^{2}+ \\
& 0.033 X_{3}^{2}+3.936 X_{1} X_{2}-1.095 X_{1} X_{3}
\end{aligned}
$$

Equation 7 represents the relationship between $\mathrm{NaOH}$ concentration $\left(X_{1}\right)$, soaking time $\left(X_{2}\right)$ and drying time $\left(X_{3}\right)$ towards $G_{I C}$ value of treated bamboo. This equation was also used to generate predictions of the response for a given level of each variable. Table 3 depicts the predicted $G_{I C}$ values using Equation 7 and the experimental finding value. It is in good agreement between the yield predicted and the experimental responses, with a small difference in $G_{I C}$ value are measured 
Table 2. The effect of treatment conditions on $G_{I C}$ values of bamboo

\begin{tabular}{|c|c|c|c|c|c|c|}
\hline No. & $\begin{array}{c}\mathrm{NaOH} \\
\text { concentration, } \\
X_{1}(\text { wt.\%) } \\
\end{array}$ & $\begin{array}{c}\text { Soaking } \\
\text { time, } X_{2} \\
\text { (hours) }\end{array}$ & $\begin{array}{l}\text { Drying } \\
\text { time, } X_{3} \\
\text { (hours) }\end{array}$ & $\begin{array}{l}\text { Measurement } \\
\text { numbers, } k\end{array}$ & $\begin{array}{c}\text { Sample } \\
\text { numbers, } \\
n\end{array}$ & $\underset{\left.\mathbf{m}^{2}\right)}{\operatorname{Mean} G_{I C}(\mathbf{J} /}$ \\
\hline 0 & 0 & 0 & 0 & 30 & 3 & 365.20 \\
\hline 1 & 1 & 3 & 48 & 35 & 3 & 362.85 \\
\hline 2 & 1 & 6 & 24 & 33 & 3 & 314.88 \\
\hline 3 & 1 & 6 & 72 & 34 & 3 & 356.94 \\
\hline 4 & 1 & 9 & 48 & 33 & 3 & 251.32 \\
\hline 5 & 2 & 3 & 24 & 33 & 3 & 270.83 \\
\hline 6 & 2 & 3 & 72 & 33 & 3 & 264.13 \\
\hline 7 & 2 & 6 & 48 & 53 & 5 & 205.48 \\
\hline 8 & 2 & 9 & 24 & 30 & 3 & 186.11 \\
\hline 9 & 2 & 9 & 72 & 30 & 3 & 163.97 \\
\hline 10 & 3 & 3 & 48 & 30 & 3 & 185.06 \\
\hline 11 & 3 & 6 & 24 & 32 & 3 & 200.77 \\
\hline 12 & 3 & 6 & 72 & 30 & 3 & 142.71 \\
\hline 13 & 3 & 9 & 48 & 30 & 3 & 120.76 \\
\hline
\end{tabular}

as can see in Table 3. The percentages of error are also calculated to determine the precision of calculations. Here, the error percentage of each run is less than $4 \%$, which is considered effective (Montgomery, 2005). The bamboo treated with $1 \mathrm{wt}$.\% concentration of $\mathrm{NaOH}$ offers the fracture toughness value up to $365.86 \mathrm{~J} /$ $\mathrm{m}^{2}$, which $0.82 \%$ of error from the testing result. The $G_{I C}$ value of treated bamboo specimens is declined with the increasing $\mathrm{NaOH}$ concentration and soaking time. Again, a higher $\mathrm{NaOH}$ concentration and soaking time could reduce the mechanical properties of the fibre due to the softening effect (Bledzki, Fink, \& Specht, 2004). Longer drying time, however, has a positive correlation with the response. The model afterwards was inspected statistically using the $F$-test and regression coefficient, $R^{2}$ for validity purposes.

\section{Model Accuracy Analysis Check}

Table 4 lists the statistical data for analysis of variance of $G_{I C}$ value. The coefficient of regression $\left(R^{2}\right)$ value of 0.998 implies that the model competently represents the relationship between the significant terms. In fact, the closer $R^{2}$ value to 1 , the higher reliability of the empirical model of the obtained data. A similar observation is noticed in the Adjusted $R$-squared of 0.996 where its value is almost 1, indicates 
Table 3. The BBD analysis predicted and experimental $G_{I C}$ values

\begin{tabular}{|c|c|c|c|c|c|c|c|c|c|c|}
\hline \multirow{3}{*}{ Run } & \multicolumn{6}{|c|}{ Independent Variables } & \multicolumn{3}{|c|}{$G_{\mathrm{IC}}\left(\mathbf{J} / \mathbf{m}^{2}\right)$} & \multirow{3}{*}{$\begin{array}{c}\text { Error } \\
(\%)\end{array}$} \\
\hline & \multicolumn{3}{|c|}{ Coded values } & \multicolumn{3}{|c|}{ Actual values } & \multirow{2}{*}{ Experimental } & \multirow{2}{*}{ Predicted } & \multirow{2}{*}{ Residual } & \\
\hline & $\mathrm{X}_{1}$ & $\mathbf{X}_{2}$ & $\mathbf{X}_{3}$ & $\mathrm{X}_{1}$ & $\mathbf{X}_{2}$ & $X_{3}$ & & & & \\
\hline 1 & 0 & +1 & -1 & 2 & 9 & 24 & 186.11 & 182.40 & 3.71 & 2.03 \\
\hline 2 & 0 & 0 & 0 & 2 & 6 & 48 & 205.64 & 208.42 & -2.78 & 1.33 \\
\hline 3 & 0 & -1 & -1 & 2 & 3 & 24 & 270.83 & 272.58 & -1.75 & 0.64 \\
\hline 4 & 0 & 0 & 0 & 2 & 6 & 48 & 207.19 & 208.42 & -1.23 & 0.59 \\
\hline 5 & 0 & +1 & +1 & 2 & 9 & 72 & 163.97 & 169.94 & -5.97 & 3.51 \\
\hline 6 & +1 & -1 & 0 & 3 & 3 & 48 & 185.06 & 184.32 & 0.74 & 0.40 \\
\hline 7 & 0 & 0 & 0 & 2 & 6 & 48 & 207.63 & 208.42 & -0.79 & 0.38 \\
\hline 8 & 0 & -1 & +1 & 2 & 3 & 72 & 264.13 & 260.12 & 4.01 & 1.54 \\
\hline 9 & -1 & +1 & 0 & 1 & 9 & 48 & 251.32 & 252.06 & -0.74 & 0.29 \\
\hline 10 & +1 & 0 & +1 & 3 & 6 & 72 & 142.71 & 143.60 & -0.89 & 0.62 \\
\hline 11 & 0 & 0 & 0 & 2 & 6 & 48 & 208.73 & 208.42 & 0.31 & 0.15 \\
\hline 12 & -1 & -1 & 0 & 1 & 3 & 48 & 362.85 & 365.86 & -3.01 & 0.82 \\
\hline 13 & -1 & 0 & +1 & 1 & 6 & 72 & 356.94 & 354.09 & 2.85 & 0.80 \\
\hline 14 & -1 & 0 & -1 & 1 & 6 & 24 & 314.88 & 313.99 & 0.89 & 0.28 \\
\hline 15 & 0 & 0 & 0 & 2 & 6 & 48 & 212.91 & 208.42 & 4.49 & 2.15 \\
\hline 16 & +1 & +1 & 0 & 3 & 9 & 48 & 120.76 & 117.76 & 3.00 & 2.55 \\
\hline 17 & +1 & 0 & -1 & 3 & 6 & 24 & 205.77 & 208.62 & -2.85 & 1.37 \\
\hline
\end{tabular}

that the suggested empirical model is significantly reliable. Adjusted $R$-squared of 0.996 is also in good agreement with the Predicted $R$-squared.

The coefficient of variation (C.V.) value measures the degree of precision with which treatments were executed and must be lower than 10\% (Montgomery, 2005). At the same time, a lower C.V. value implied a higher reliability of the experiment. Therefore, the C.V. value of $1.81 \%$ indicates the experiment conducted in this study is reliable. Meanwhile, Adequate Precision value measures the signal to noise ratio were a ratio greater than 4 are desirable (Montgomery, 2005). The ratio for the studied model of 82.783 indicates an adequate signal, thus suggests the proposed model can be utilized to navigate the design space.

\section{Response Analysis}

The adequacy of the model is inspected to verify whether the suggested model provides sufficient approximation to the actual system (Shao, Fang, \& Tian, 2009). 
Table 4. The statistical data of ANOVA for $G_{I C}$

\begin{tabular}{|l|c|}
\hline \multicolumn{1}{|c|}{ Source } & Response value \\
\hline R-Squared $\left(R^{2}\right)$ & 0.998 \\
\hline Adjusted R-Squared & 0.996 \\
\hline Predicted R-Squared & 0.987 \\
\hline Standard Deviation & 4.120 \\
\hline Coefficient of Variation (C.V.) $(\%)$ & 1.810 \\
\hline Adequate Precision & 82.783 \\
\hline Mean & 227.500 \\
\hline
\end{tabular}

To evaluate the model satisfaction, the internal studentised residuals can be verified with the assumption of ANOVA. Here, the internally studentised residual is used to obtain the standard deviation between the experiment and predicted values. Figure 5 presents a relationship of normal probability distribution and the internally studentised residuals. All the residuals point fall closer to the line and fits with the model of the data as can be observed in Figure 5. It can be suggested that no response transformation is required. In addition, the examine residual is also having no apparent problem with the normality.

Figure 5. The normal probability plot of residuals

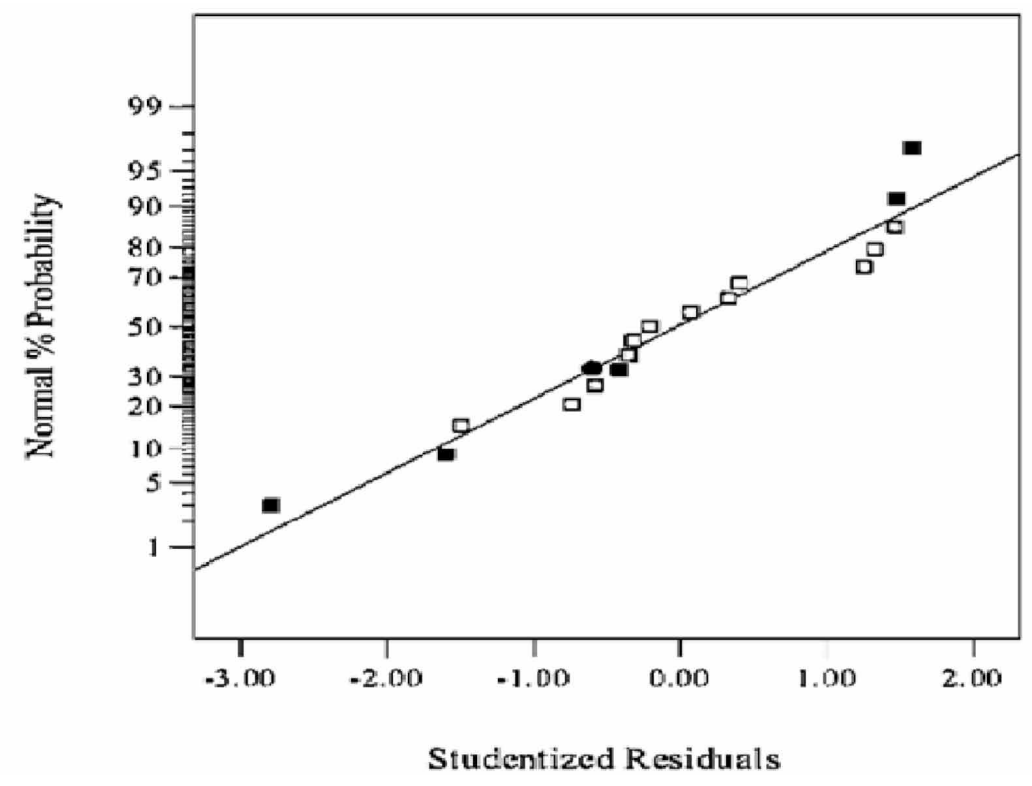


Figure 6 shows the relationship between studentized residuals and predicted response. In this figure, the studentized residuals was scattered randomly and spread in a constant range across the plot around the " 0 " line. It is indicated that no clear patterns in this plots and validating the initial assumption of constant variance competently. As can be seen from the Figure 6, the residuals and thus confirmed the adequacy of the model. Figure 7 presents a correlation between the experimental and predicted values of $G_{I C}$. Here, all scatter points are properly distributed close to the line, which suggests a high degree of correlation between the experiment and predicted values. It is therefore suggested that the closer data points to the reference line, the greater accuracy of the model (Montgomery, 2005). Thereby, all the fundamental analyses described are closely fitted, and the selected empirical model is acceptable in predicting the $G_{I C}$ value.

In order to attain a better understanding of the results, the perturbation plot that provides a silhouette view of the response surface is presented in Figure 8. The perturbation plot demonstrates the response of a particular variable as it moves from the chosen reference point while the other variables are fixed to this point. In the Design-Expert software, the reference point is set at the centre of the design space that is the zero-coded level of each variable. So, the zero-coded level of each variable in this study is $\mathrm{NaOH}$ concentration $\left(X_{1}\right)=2.00$, soaking time $\left(X_{2}\right)=6.00$ and drying time $\left(X_{3}\right)=48.00$. From Figure 8 , the increasing variables $X_{1}$ and $X_{2}$ clearly

Figure 6. The plot of studentized residuals versus predicted response

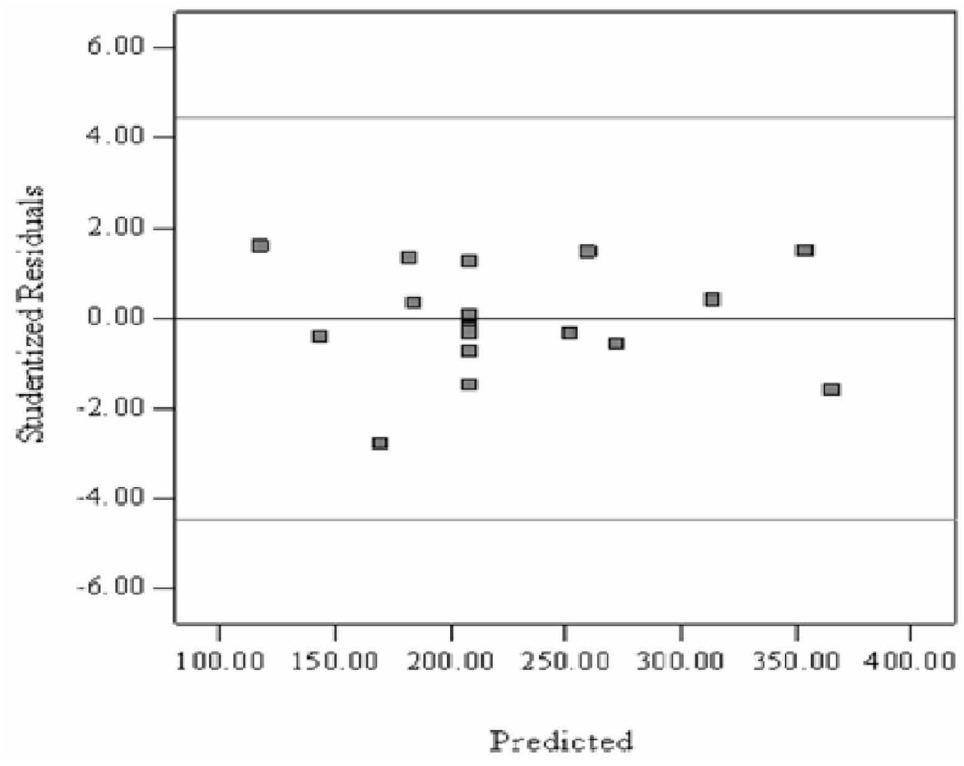


Figure 7. The plot of the predicted versus actual response

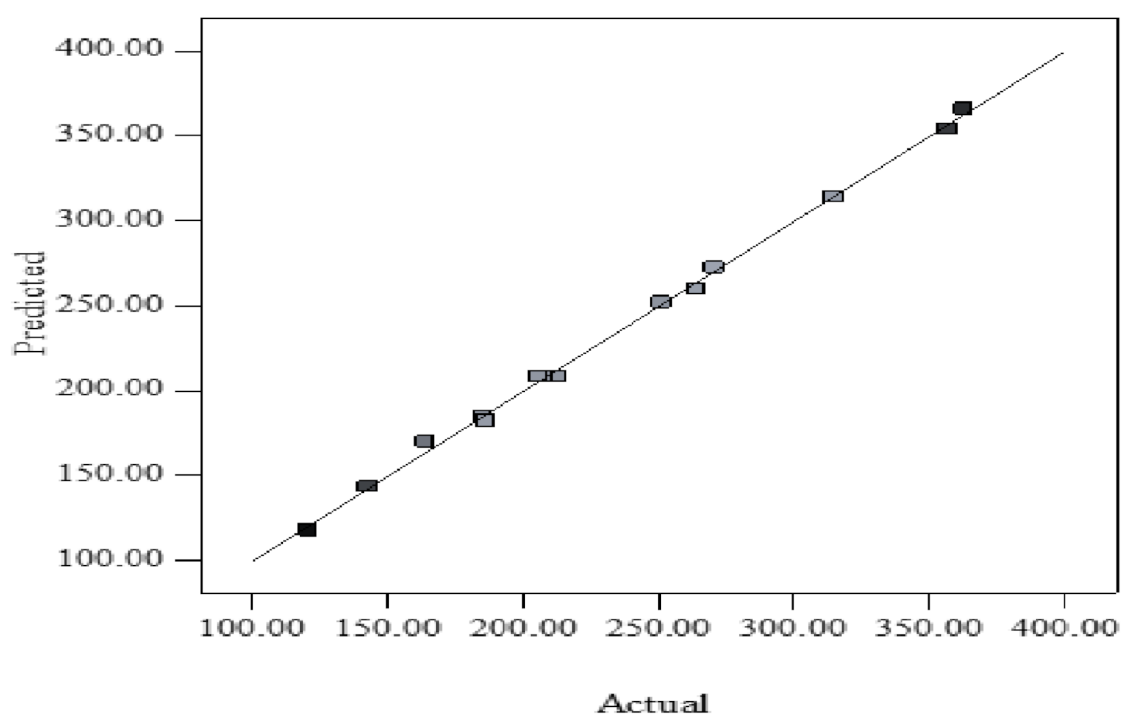

offer negative effect on $G_{I C}$ values. Conversely, variable $X_{3}$ shows a slight positive effect on $G_{\mathrm{IC}}$ values of bamboo where the $G_{\mathrm{IC}}$ values increase with increasing $X_{3}$.

The contour plots and response surface for the interaction effect of $\mathrm{NaOH}$ concentration $\left(\mathrm{X}_{1}\right)$ and soaking time $\left(\mathrm{X}_{2}\right)$ on $\mathrm{G}_{\mathrm{IC}}$ values of bamboo at 72 hours of drying time $\left(X_{3}\right)$ are presented in Figure 9 . The highest $\mathrm{G}_{\mathrm{IC}}$ value of $365.86 \mathrm{~J} / \mathrm{m}^{2}$ was recorded at the lowest $\mathrm{NaOH}(1 \% \mathrm{wt})$ concentration and 3 hours of soaking time.

\section{Validation of Optimization Process}

Validation experiments are conducted to determine the performance of chemical treatment by evaluating the level of concentration, drying time and soaking duration studies at the optimum favorable conditions through Design Expert Software. The results recorded at $(1.5 \% \mathrm{wt}) \mathrm{NaOH}$ concentration, 2.85 hours of soaking time and 72.5 hours of drying time $\left(\mathrm{X}_{3}\right)$ offers the highest $\mathrm{G}_{\mathrm{IC}}$ value of $367.25 \mathrm{~J} / \mathrm{m}^{2}$. Three additional experiments are repeated and the average value for Mode 1 fracture is approximately $85 \%$.

\section{CONCLUSION}

Based on the statistical analysis conducted using ANOVA, the proposed variables are found to significantly influence the $G_{\text {IC }}$ values of treated bamboo. The analysis 
Figure 8. The perturbation plot of the effect of all variables on $G_{I C}$ value

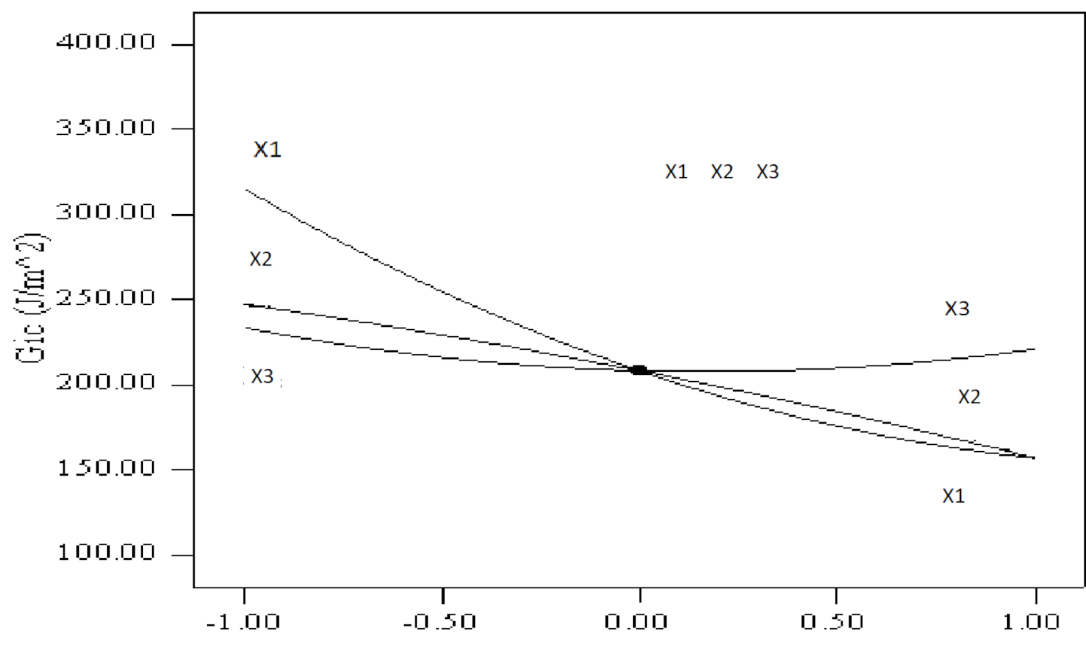

Deviation from Fefetence Faint

Figure 9. The effect of $\mathrm{NaOH}$ and drying time on $G_{I C}$ value

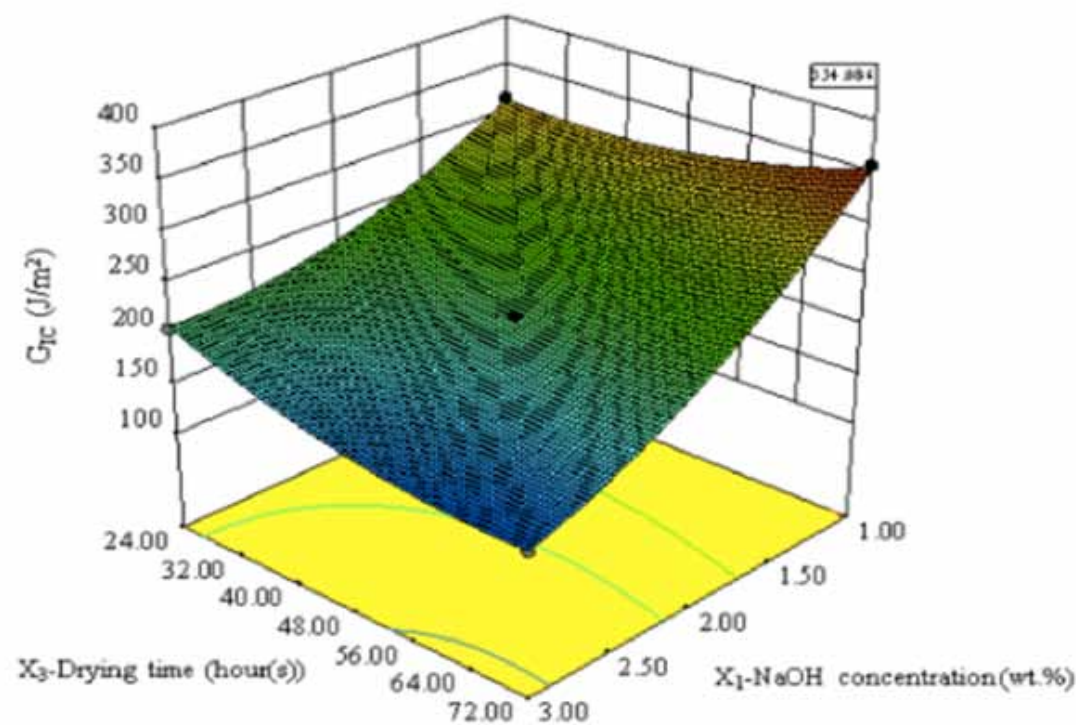

suggested that the bamboo needs to be treated with low $\mathrm{NaOH}$ concentration for a short soaking period and dried at a longer drying time, to obtain the optimum $G_{\text {IC }}$ value of bamboo at room temperature. The highest value of $G_{I C}$ for treated 
bamboo is evaluated at $367.25 \mathrm{~J} / \mathrm{m}^{2}$ when the bamboo treated with $1.5 \mathrm{wt} \%$ of $\mathrm{NaOH}$ concentration for 2.85 hours and dried up to 72.5 hours at room temperature (1.5wt.\%-2.85hours-72.5hours).

\section{ACKNOWLEDGMENT}

The appreciation is given to Universiti Teknologi Malaysia and Ministry of Higher Education under Fundamental Research Grant Scheme [R.K130000.7840.4F880] and "Geran Universiti Penyelidik' (GUP) Tier 1 [Q.K130000.2540.15H70] for financially support provided throughout the course of this research project.

\section{REFERENCES}

American Society for Testing and Materials (ASTM). (2001). Standard test for Mode I interlaminar fracture toughness of unidirectional fibre-reinforced polymer matrix composites. Philadelphia: D 5528-01.

Ariawan, D., Mohd Ishak, Z. A., Salim, M. S., Mat Taib, R., \& Ahmad Thirmizir, M. Z. (2017). Wettability and interfacial characterization of alkaline treated kenaf fiber-unsaturated polyester composites fabricated by resin transfer molding. Polymer Composites, 38(3), 507-515. doi:10.1002/pc.23609

Bakhori, S., Hassan, M. Z., Daud, Y., Sarip, S., Rahman, N., Ismail, Z., \& Aziz, S. A. (2015). Mechanical behavior of Kenaf/Epoxy corrugated sandwich structures. IOP Conference Series. Materials Science and Engineering, 100(1), 012011. doi:10.1088/1757-899X/100/1/012011

Bakhori, S. N. M., Zuikafly, S. N. F., Ahmad, F., \& Hassan, M. Z. (2017). Tensile properties for MWCNT filled jute-Epoxy composites. Journal of Advanced Research in Applied Mechanics, 31(1), 16-21.

Bledzki, A. K., Fink, H. P., \& Specht, K. (2004). Unidirectional hemp and flax EP- and PP composites: Influence of defined fibre treatments. Journal of Applied Polymer Science, 93(1), 2150-2156. doi:10.1002/app.20712

Chen, H., Yu, Y., Zhong, T., Wu, Y., Li, Y., Wu, Z., \& Fei, B. (2017). Effect of alkali treatment on microstructure and mechanical properties of individual bamboo fibers. Cellulose (London, England), 24(1), 333-347. doi:10.100710570-016-1116-6 
Islam, M. S. (2008). The influence of fibre processing and treatments on hemp fibrelepoxy and hemp fibre/pla composites (Unpublished doctoral dissertation). The University of Waikato, Hamilton, New Zealand.

Khan, Z., Yousif, B. F., \& Islam, M. (2017). Fracture behaviour of bamboo fiber reinforced epoxy composites. Composites. Part B, Engineering, 116, 186-199. doi:10.1016/j.compositesb.2017.02.015

Liu, Z., Li, L., Liu, C., \& Xu, A. (2018). Pretreatment of corn straw using the alkaline solution of ionic liquids. Bioresource Technology, 260, 417-420. doi:10.1016/j. biortech.2018.03.117 PMID:29631854

Mishra, S., Mohanty, A., Drzal, L., Misra, M., Parija, S., Nayak, K., \& Tripathy, S. (2003). Studies on mechanical performance of biofibre/glass reinforced polyester hybrid composites. Composites Science and Technology, 63(10), 1377-1385. doi:10.1016/S0266-3538(03)00084-8

Montgomery, D. C. (2005). Design and Analysis of Experiments (6th ed.). New York: John Wiley \& Sons, Inc.

Rao, R., Varada, R., Ramachandra, R., \& Hemachandra, K. (2010). Flexural and compressive properties of bamboo and glass fibre-reinforced epoxy hybrid composites. Journal of Reinforced Plastics and Composites, 29(10), 1446-1450. doi:10.1177/0731684409105077

Reddy, B. R., \& Dhoria, S. H. (2018). Effect of alkaline treatment on mechanical properties of kenaf fiber reinforced polyester composites. In AIP Conference Proceedings: Vol. 1943. No.l (p. 020097). AIP Publishing. doi:10.1063/1.5029673

Shao, Z., Fang, C., \& Tian, G. (2009). Mode I interlaminar fracture property of moso bamboo. Wood Science and Technology, 43(5), 527-536. doi:10.100700226009-0265-2

Singh, V. K., Mukhopadhyay, S., \& Das, D. (2017). Recipe optimisation for sugarcane bagasse fibre reinforced soy protein biocomposite. Indian Journal of Fibre and Textile Research, 42(2), 132-137.

Yaghoobi, H., \& Fereidoon, A. (2018). Modeling and optimization of tensile strength and modulus of polypropylene/kenaf fiber biocomposites using Box-Behnken response surface method.Polymer Composites, 39,E463-E479. doi:10.1002/pc.24596 
Yan, L., Chouw, N., Huang, L., \& Kasal, B. (2016). Effect of alkali treatment on microstructure and mechanical properties of coir fibres, coir fibre reinforced-polymer composites and reinforced-cementitious composites. Construction \& Building Materials, 112, 168-182. doi:10.1016/j.conbuildmat.2016.02.182

Yang, X., Shang, L., Xing'e, L., Shumin, Y., \& Genlin, T. (2017). Changes in bamboo fiber subjected to different chemical treatments and freeze-drying as measured by nanoindentation. Journal of Wood Science, 63(1), 24-30. doi:10.100710086-0161590-3

Yu, Y., Jiang, Z., Fei, B., Wang, G., \& Wang, H. (2011). An improved microtensile technique for mechanical characterization of short plant fibers: A case study on bamboo fibers. Journal of Materials Science, 46(3), 739-746. doi:10.100710853010-4806-8 